\title{
Sustainable development of the coastal regions: problems, prerequisites, and limitations
}

\author{
P.Ya. Baklanov* \\ Pacific Institute of Geography, Far Eastern Branch of the Russian Academy of Sciences, Vladivostok, \\ Russia
}

\begin{abstract}
Sustainable development of a region is considered as stable development, balanced in the economic, social and environmental areas. To achieve sustainable development of a coastal region, it is necessary to cover the entire integral geosystem, including land territory of the region and the adjacent sea area. It is necessary to model dynamics of the geosystem using various information and geographic information systems. On this basis, strategic planning and monitoring of the sustainable development should be employed. Basic core principle for the sustainable development of coastal regions is a regional nature management, including usage of the natural resources of land, sea and ocean. At the same time, it is necessary to identify and evaluate aqua-territorial combinations of the natural resources and interresource ties. There are some problems and limitations of the sustainable development of coastal regions, which are highlighted, including dangerous processes and phenomena (wave, tsunami, typhoons, etc.), the need for coastal protection, etc., as well as favorable factors - availability of various marine natural resources, possibility of using sea transport and availability of sea markets, etc.
\end{abstract}

\section{Introduction}

In the global problem of sustainable development of countries and regions, a large scientific component remains unresolved - in the justification of principles, mechanisms, indicators, ways of achieving and managing, and an even larger one-in their practical implementation. To date, it can be considered reasonable that sustainable development is based on stable qualitative and quantitative increments in the economic and social sphere and qualitative ones in the environmental sphere of the country or region and their balanced development $(1,2$, $3,4,5,6,7,8)$. Despite the commonality of this approach to sustainable development in all regions, there are significant differences in the initial problems and constraints, as well as factors and ways to achieve them for different types of areas, including continental, coastal, and transboundary ones $(6,7,8,9,10,11,12,13)$.

\footnotetext{
* Corresponding author: baklanov@tigdvo.ru
} 


\section{Materials and methods}

The authors used scientific literature, regional development programs, methods of comparative and geosystem analysis, and a forecast-geographical approach.

\section{Results and discussions}

Numerous studies of the problems of sustainable development of regions, including our own, show that in order to achieve stable development, balanced in the social, economic and environmental spheres of the region, the following conditions must be met.

1. The scope of a complete geographical system, including its natural, natural-resource, ecological and socio-economic structures, that is, it is necessary to consider the entire integrated geographical system.

2. It is necessary to cover the dynamics of this geographical system over a long period of time, including in the forecast period.

3. It is necessary to model the structure and dynamics of an integrated geographical system and calculate a balanced version of its sustainable development.

4. Strategic planning and ongoing operational management are needed to develop and implement a sustainable development model. And the object of analysis, modeling, calculations, planning and management should be an integrated geographical system or a combination of them, allocated within a region, for example, a subject of the Russian Federation.

5. For such modeling, planning and management, a wide variety of information is needed. First, it should be systematized, linked to the territory, including in the form of appropriate regional geographic information systems, and, secondly, continuously updated by monitoring the changing structures of the geographical system and periodic forecast calculations.

6. Ultimately, it is necessary to organize regional monitoring of sustainable development, the most important component of which should be monitoring of regional environmental management (14).

For the coastal regions, first of all, the formation of contact structures and functions is characteristic - in the natural-ecological sphere, natural-resource and socio-economic. As a result, aqua-territorial structures are formed in these areas $(6,12)$. Therefore, the main object of analysis, modeling, planning and management should be allocated to the territorial-water region, which includes the territory of the Primorsky district and the adjacent space of the sea area within the 200-mile marine exclusive zone. The overall integrated geographical system will consist of a combination of land-based, territorial geographical systems, coastal-marine aqua-territorial and marine, aquatic geographical systems that are somehow connected and interact with each other.

In general, the following problems and limitations can be identified, as well as favorable factors and prerequisites for achieving sustainable development in the coastal regions (table 1).

Table 1. General problems and limitations, favorable factors and prerequisites for the sustainable development of the coastal regions

\begin{tabular}{|l|l|}
\hline \multicolumn{1}{|c|}{ Problems, limitations } & \multicolumn{1}{|c|}{ Favorable factors and prerequisites } \\
\hline $\begin{array}{l}\text { Negative impact of marine hazards } \\
\text { (sea waves, including tsunamis, } \\
\text { storms, typhoons, etc.). }\end{array}$ & $\begin{array}{l}\text { Availability of a variety of marine natural resources, } \\
\text { including many renewable (biological, energy, recreational). }\end{array}$ \\
\hline $\begin{array}{l}\text { The need to strengthen sea coasts, } \\
\text { create expensive coastal protection } \\
\text { systems. }\end{array}$ & $\begin{array}{l}\text { The possibility of widespread use of cheaper sea transport. } \\
\text { Accessibility and the possibility of using many markets } \\
\text { adjacent to the relevant water areas. }\end{array}$ \\
\hline
\end{tabular}


Coastal-marine zones (and geographical systems) and a network of coastal settlements play an important role in the sustainable development of marine regions. On the one hand, they ensure the development and use of marine natural resources, marine transport potential, and on the other hand, they are links between marine and terrestrial geographical systems and their structures.

Regional environmental management and its spatial structures play a basic role in the sustainable development of the coastal regions (14). The main principle of their formation and functioning should be the maximum long-term conservation of natural resource potential-both in terrestrial geographical systems and in marine ones. Therefore, the most important task of monitoring regional environmental management should be considered tracking the dynamics of the natural resource potential of land and marine geographical systems in the conditions of their development and socio-economic development of the region.

We have shown that natural resources both within the land and the sea do not exist in isolation from each other, but in various connections and relationships, that is, in the form of territorial and aqua-territorial natural resource combinations and systems [12]. In this regard, the dynamics, including the extraction of one natural resource within an integral geographical system, leads to changes in other natural resources associated with it, including through the mechanisms of geographical systems.

In order to reliably control all possible balanced dynamics of natural resources, it is necessary to cover all their territorial and aqua-territorial combinations with inter-resource links. It seems that the existence of close inter-resource relations in integrated geographical systems is the objective reason for the incompatibility of private ownership of individual natural resources and their zones, including marine ones, with the principles and achievement of sustainable development. In this regard, the main object of assessments, planning, development and management, and, accordingly, property relations, should be such territorial and aqua-territorial natural resource systems.

In the social sphere, it is necessary to achieve a sharp reduction in contrasts, differences in the level of income and quality of life of individual groups of the population, both in the country and in the region. In this regard, for the coastal regions, people's enterprises with a collective (people's) form of ownership, including in the field of extensive development of marine natural resources, may be more effective in the system of sustainable development. This is also linked to the collective (people's) form of ownership of the natural resources of the land and sea.

As integral criteria of sustainable development, we have proposed criteria for the quality of regional development - economic, social and environmental $(6,7)$. Economic and social quality indicators reflect quantitative and qualitative increments in the economic and social spheres of the region. Environmental quality-reflects the improvement of the environment and the minimum reduction of the natural resource potential of the region-in terms of nonrenewable resources and non - reduction-renewable.

\section{Conclusion, main conclusions}

The main object of assessments, analysis, strategic planning and management of the regional sustainable development of the Primorsky region should be identified as a territorial-water area in the form of a combination of integrated geographical systems.

It is necessary to model the structural dynamics of this region, on this basis - the calculation of forecast options and the choice of a model that corresponds to sustainable development.

Strategic planning should involve a variety of information, including on neighboring regions and geographical systems, and make extensive use of geoinformation and digital 
technologies. If the coastal area is part of a transboundary region, for example, a transboundary river or sea basin, it is necessary to use different information for the entire transboundary region. This is due to the presence of close interdependencies in the dynamics, including the development of certain parts of cross-border regions and geographical systems $(12,13)$.

Ultimately, it is advisable to create a regional monitoring of sustainable development, based on geoinformation and digital basis and periodic modeling of the forecast dynamics of the integrated geographical systems of the region.

\section{Acknowledgements}

The article was prepared with the financial support of the grant of the Russian Foundation for Basic Research, project No. 18-05-80006.

\section{References}

1. N.T. Agafonov, R.A. Islyaev, The main provisions of the transition of the Russian Federation to the model of sustainable development, Center for Regional Policy Research and Design. St. Petersburg, 117 (1995)

2. The concept of sustainable development: stereotypes and reality (Concept of the Russian Geographical Society), Geographic problems of the strategy of sustainable development of the natural environment and society, 42

3. K.Ya. Kondratev, News Russian Geographical Society, 126(9), 1 (1997)

4. N.F. Glazovsky, Geographical aspects of the problem of transition to sustainable development of the Commonwealth of Independent States. Kiev. M.: Association of the Scientific Council on Fundamental Geographical Problems M.: Russian Academy of Sciences, 21 (1999)

5. V.S. Tikunov, D.A. Tsapuk, Sustainable development of territories: cartographic and geoinformation support, 173 (1999)

6. P.Ya. Baklanov, The Far Eastern region of Russia: problems and prerequisites for sustainable development, 144 (2001)

7. P.Ya. Baklanov, University geography. Materials of the anniversary scientific conference, Geographical Faculty of the Moscow State University, 30 (2005)

8. Transition to sustainable development: global, regional and local levels. Foreign experience and problems of Russia, 444 (2002)

9. A.K. Tulokhonov, Baikal regions: problems of sustainable development, 208

10. Yu.I. Vinokurov, B.A. Krasnoyarova, V.I. Ovdienko, Sustainable development of Siberian regions, 240 (2003)

11. Geographical studies of Siberia. T. 1. Structure and dynamics of geographical systems / Yu.M. Semenov, A.V. Belov, E.G. Suvorov and et ., 413 (2007)

12. Geographical systems of the Far East at the turn of the XX and XXI centuries. T. II. Natural resources and regional nature management, edited by P. Ya. Baklanov and V. P. Karakin, 560 (2010)

13. G.M. Fedorov, V.S. Korneevets, Baltic Region, 2, 32 (2009)

14. P.Ya. Baklanov, Geography and Natural Resources, 1, 5 (2019) 